\author{
Denise R. Jones \\ and \\ Steven D. Young \\ NASA Langley Research Center \\ Hampton, Virginia 23681 \\ Presented at the 13th AIAA/IEEE \\ DIGITAL AVIONICS SYSTEMS CONFERENCE
}

Phoenix, Arizona

October 31 - November 3, 1994 



\title{
ENHANCING PILOT SITUATIONAL AWARENESS OF THE AIRPORT SURFACE MOVEMENT AREA
}

\author{
Denise R. Jones and Steven D. Young \\ NASA Langley Research Center
}

\begin{abstract}
Two studies are being conducted to address airport surface movement area safety and capacity issues by providing enhanced situational awareness information to pilots. One study focuses on obtaining pilot opinion of the Runway Status Light System (RSLS). This system has been designed to reduce the likelihood of runway incursions by informing pilots when a runway is occupied. The second study is a night demonstration of an integrated system consisting of an electronic moving map in the cockpit and display of the aircraft identification to the controller. Taxi route and hold bar clearances, positions of other traffic, and warning information will be sent to the aircraft via data link for display on the electronic moving map. This paper describes the plans for the two studies.
\end{abstract}

\section{INTRODUCTION}

Air traffic is expected to increase significantly in the 21 st century. With geographical, environmental, and zoning restrictions placed on most major U.S. airports, expansion is prohibited. Therefore, action must be taken to increase the capacity and safety of existing airport facilities. One area of focus is the airport surface movement area. The Federal Aviation Administration (FAA) has established the Airport Surface Traffic Automation (ASTA) program to enhance safety and optimize the flow of traffic on the airport surface. The ASTA program plans to address these concerns by providing air traffic control, the airlines, and airfield management with positive identification of surface targets on the movement area; providing pilots with airfield safety alerts; providing controllers with automated warnings of potential and actual runway incursions; providing a surface traffic planning capability; and providing an automated method of sending instructions, such as taxi route clearances, to aircraft. 1

${ }^{1}$ ASTA description obtained from the ASTA System Design Overview, Federal Aviation Administration.
Similarly, the National Aeronautics and Space Administration's (NASA) Terminal Area Productivity (TAP) Program is focused on providing technology and operating procedures for safely achieving clearweather capacity in instrument-weather conditions. In cooperation with the FAA, NASA's approach is to develop and demonstrate airborne and ground technology and procedures to safely reduce aircraft spacing in the terminal area, enhance air traffic management, reduce controller workload, improve low visibility landing and surface operations, and integrate aircraft and air traffic systems.

This paper describes two research efforts being conducted at the NASA Langley Research Center (LaRC) which address many of the issues of both the ASTA and TAP programs.

\section{RUNWAY STATUS LIGHT SYSTEM EVALUATION STUDY}

The Runway Status Light System (RSLS) has been developed by the FAA in coordination with MITLincoln Labs [1]. The objective of the RSLS is to improve airport safety by preventing runway incursions by both aircraft and ground vehicles. Runway incursions are caused by human error usually brought on by a lack of situational awareness, failure to properly communicate, or navigation errors. RSLS is intended to minimize the effect of human errors by providing an automatic backup system.

The purpose of the RSLS is to convey the status of a runway, indicating whether or not a runway is active. It is not intended to convey clearance to proceed onto a runway. The RSLS is intended for use in all weather conditions and at all times of the day or night.

The RSLS is a system of lights automatically controlled using surface radar data (figure 1). There are two types of lights that make up the RSLS. Takeoff Hold Lights (THLs) are positioned to wam pilots, who are ready to takeoff, when the runway is presently not clear or that other aircraft are projected to 


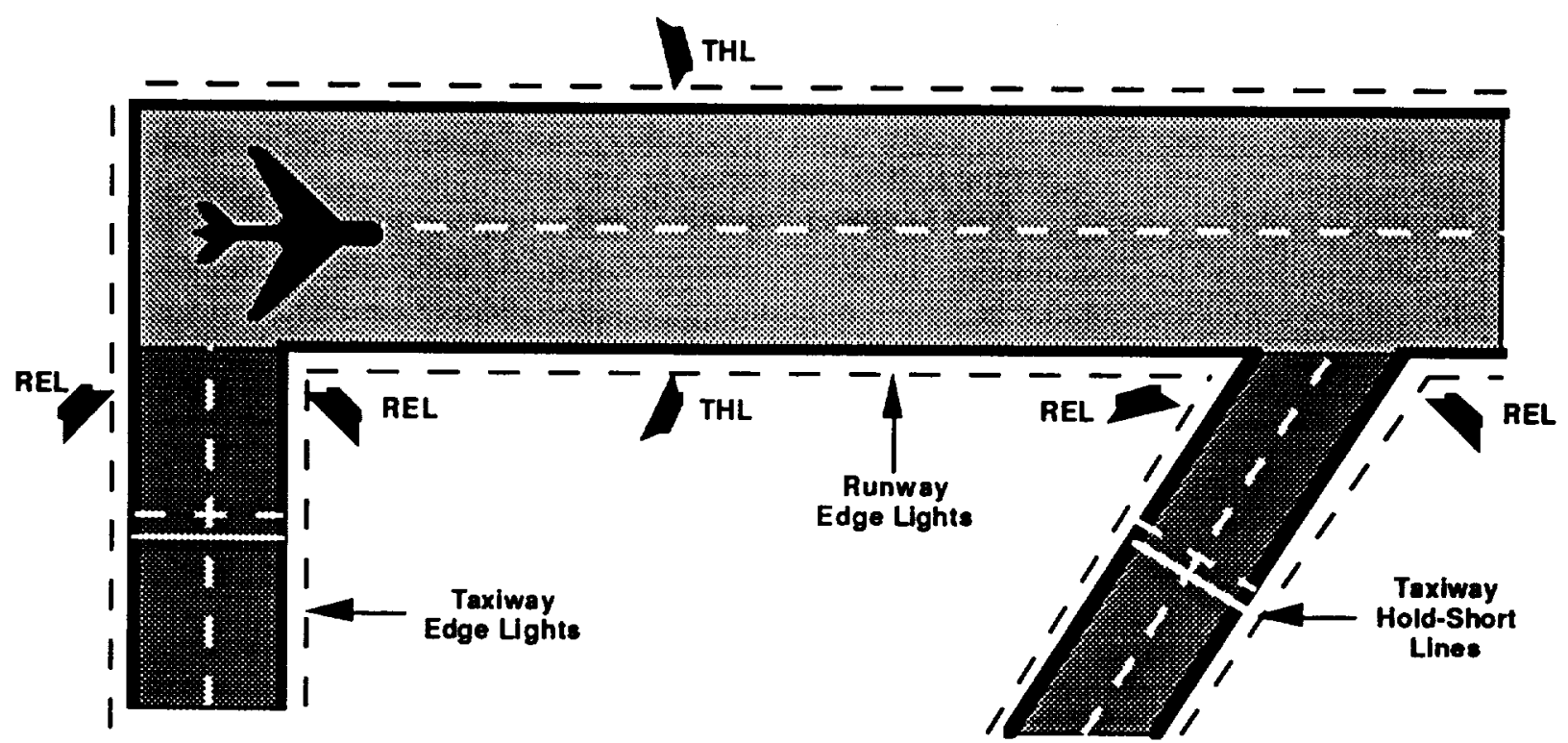

Figure 1. Runway Status Light System (RSLS).

enter the runway in front of the takeoff. THLs are positioned on either side of runways ahead of the takeoff hold position. Runway Entrance Lights (RELs) are designed to inform pilots (or ground vehicle operators) when a runway is unsafe to enter. RELs are positioned on either side of taxiways just prior to the intersection of the taxiway and the runway. Both THLs and RELs are bright red when "on".

\section{RSLS Objectives}

The primary goal of the RSLS is to improve airport safety by preventing most runway conflicts, independent of controller clearance. The lights serve as an automatic safety feature that guards against both controller and pilot error.

Specific objectives of the RSLS are to improve pilot situational awareness, prevent certain high-speed crossing conflicts, and prevent conflicts on the same or on crossing runways. The RSLS should not cause confusion to pilots, increase pilot workload, adversely affect traffic flow, or convey clearance.

An initial prototype of the RSLS is planned for installation at the Boston-Logan International airport sometime in 1995 . This prototype system will be used in extensive trials to fine-tune the RSLS in an operational airport environment. Prior to these trials, the FAA determined the need for pilot evaluation of a RSLS prototype concept in a simulated environment. Feedback from the pilot community during the early stages of system development could provide support for not only the trial system in Boston, but also the final production system that would evolve from these prototypes.

Because of NASA LaRC's history of high fidelity flight simulation tests, its realistic cockpit environments, and its common interests in improving terminal area productivity, the FAA requested that NASA LaRC conduct a flight simulation study that would both implement a conceptual prototype and allow for piloted evaluations of the RSLS.

\section{Pilot Evaluation Goals}

The primary goal of the study is to obtain pilot opinion of potential usefulness of this lighting system for decreasing incursions on the airport surface.

Secondary goals are to: (1) determine the impact of the system in a realistic cockpit environment (e.g. Is it confusing? Does it add to pilot workload?); (2) acquire suggestions for operational procedures and areas of improvement; and (3) help with design issues such as light size, directionality, and location.

\section{Flight Simulation Approach}

Initial pilot opinion of the proposed RSLS is obtained through a series of flight simulations performed using the Transport Systems Research Vehicle (TSRV) simulator located at NASA LaRC. The TSRV simulator emulates the cockpit of a modified Boeing 737 and includes electronic displays and side-arm controllers. The lights that make up the RSLS are constructed and located on the "out-the-window" scene visible to pilots who use the TSRV simulator. The 
Denver-Stapleton International airport was selected for this study.

Pilots are briefed on the purpose and limitations of the RSLS simulated demonstrations and are given the opportunity to become familiar with the flight simulator environment. The pilots are asked to operate the simulated aircraft during several test scenarios. These scenarios allow the pilots to evaluate the RSLS under various operational and situational conditions. Pilots are asked to answer several questions both before and after the simulation sessions; responses are accumulated and a document will be drafted which captures the essence of the response data.

\section{Flight Simulation Implementation}

To perform the evaluations described above, it was necessary to depict REL and THL light fixtures in the computer-generated image (CGI) database of the Denver-Stapleton airport. Unfortunately, there is a limitation on the number of lights that can be resident in a CGI database. To avoid surpassing the light budget of the simulator, runway status lights were only added on runways $8 \mathrm{~L} / 26 \mathrm{R}$ and $8 \mathrm{R} / 26 \mathrm{~L}$. These are the two parallel runways on the south side of DenverStapleton.

Test scenarios were developed that allow pilots to observe the behavior of the runway status lights under various conditions such as day/night, different visibilities, and different traffic patterns. Departure scenarios start after pushback on the initial taxiway in the controlled area and end just after takeoff. Arrival scenarios start on final approach (about 3 miles out) and end at the ramp. Crews are asked to perform normal operational workload during each scenario (e.g. checklists and radio communications).

Air traffic control personnel (both the ground controller and the tower controller) are situated at a remote location with real-time displays of the simulated traffic available. The staff controller not only communicates with the test subjects during the scenarios, but also emulates voice traffic for other aircraft in the field of view of the test subjects.

Crews are subjected to 10 scenarios which take about 2 hours of simulation time. All cockpit audio and video are recorded. A top-level animated view of the airport activity which allows an alternate perspective of the sequence of events that occur during the simulated flight tests is also recorded.

\section{Subject Pool}

Over 20 pilots will be used as test subjects in the evaluation study. Participating pilots will come mainly from commercial airlines via the Airline Pilots Association, but also from NASA, and the general aviation community. The experience of the commercial pilots ranges from 5,300 to over 17,000 flight hours.

\section{FLIGHT DEMONSTRATION OF ASTA CONCEPTS}

The Flight Demonstration of ASTA Concepts (FDAC) is part of the NASA TAP Low Visibility Landing and Surface Operations (LVLASO) Program. The demonstration is being conducted in conjunction with industry partners from Westinghouse Norden Systems and Aeronautical Radio, Incorporated (ARINC). The goal of the demonstration is to provide the pilot with enhanced situational awareness information to improve safety and increase traffic capacity of the airport surface movement area. The FDAC will be conducted at the Atlantic City International (ACY) airport with the cooperation of the FAA Technical Center. If time permits, an additional demonstration will occur at the Naval Air Weapons Center at Patuxent River, Maryland.

\section{General Description}

During the FDAC, an air traffic controller will data link [2] approved taxi route and hold short clearances to a NASA research aircraft for display on an electronic moving map of the ACY airport. Positions of other relevant traffic and warning information will also be sent to the aircraft for display on the moving map. Additionally, the identification of the aircraft will be shown on the controller's surface radar display next to the aircraft's symbol. Various departure and arrival scenarios will be demonstrated. Some of these scenarios will include modifications to the approved taxi route and simulated runway incursions with other traffic. Although the FDAC is a demonstration, subjective comments will be obtained on the effectiveness and content of each subsystem. It is also planned to record aircraft position data from all available sources for comparison of accuracy and to examine all data transmission rates for acceptability. An audio record will be made of the pilot/controller correspondence and video will be taken from several angles for post analysis. 


\section{Systems Description}

The FDAC will demonstrate an integration of technologies developed by each of the partners (figure 2). The following sections describe the FDAC systems in detail.

\section{Transport Systems Research Vehicle}

The Transport Systems Research Vehicle (TSRV), a modified Boeing 737, is a NASA LaRC research aircraft [3]. The TSRV has two flight decks. The forward flight deck is a conventional Boeing 737 cockpit that provides operational support and safety backup. The "all-glass" research flight deck, located in the aircraft cabin, can be readily reconfigured to support research programs.

\section{Identification Tagging}

In order to obtain the identification of the TSRV, a transponder coded with the tail number will be mounted on the aircraft. The transponder will be interrogated by the Airport Surface Detection Equipment (ASDE-3) radar to obtain the identification. The tail number will then be sent to the communication ground station by the Airport Movement Area Safety System (AMASS) where correlation to flight number will be made. The flight number will then be transmitted to the AMASS for display on the controller's monitor. The ASDE-3 [4] is a high resolution airport ground mapping radar with maximum weather penetration capability. The AMASS [5] was designed under FAA sponsorship to enhance the surveillance and collision avoidance capabilities of the ASDE-3 radar. AMASS provides controllers with automatic conflict warnings and alerts to help prevent collisions and other runway and taxiway accidents. Both the ASDE-3 and AMASS are being installed at 37 major airports throughout the country.

\section{Electronic Moving Map}

An electronic moving map (figure 3 ) has been developed and evaluated in simulator studies [6] at NASA LaRC. For this flight demonstration, the electronic moving map will be located in the research flight deck of the TSRV. The safety pilot in the forward flight deck will be controlling the aircraft during taxi because of the location of the steering tiller. The research pilot will verbally relay routing and situation information obtained from the electronic map to the safety pilot. The situation information will include guidance in following the taxi route (when to turn, etc.), when to stop at hold lines, and the location of relevant traffic. The safety pilot will be able to determine the effectiveness of the map through the

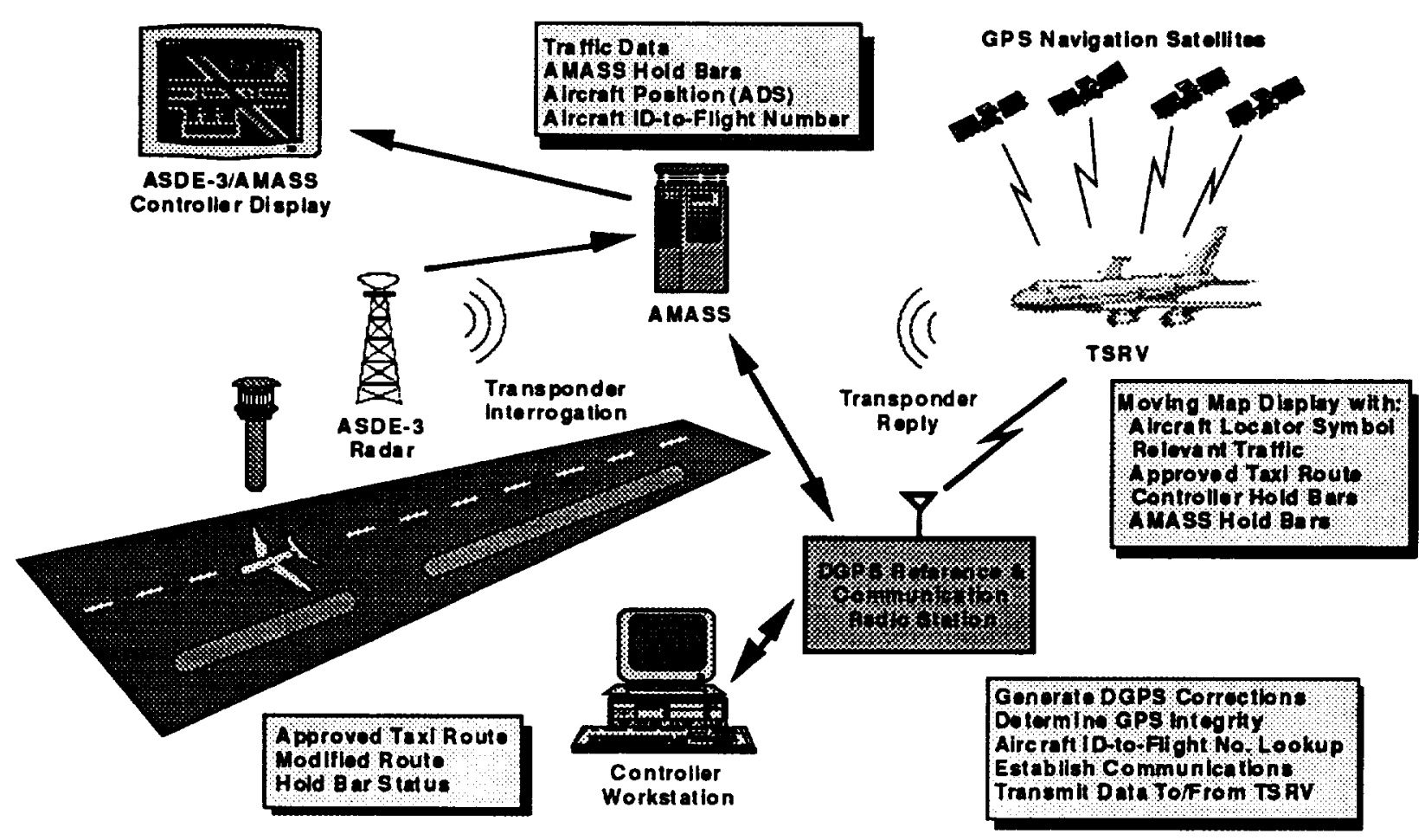

Figure 2. FDAC system description. 
situation awareness information relayed from the research pilot.

The electronic map will be generated by a graphics workstation and displayed on a liquid crystal flat panel that has a 640 by 490 pixel resolution and has dimensions of 8.5 inches by 6.5 inches. The pilot will interact with the moving map through bezel buttons located on each side of the map. The available functions include accepting the taxi route, zoom in/out, show/hide other traffic, show/hide five second position prediction indicator, track/North up mode, display an insert containing the airport, and show/hide runway/taxiway name labels.

Figure 3 shows the major components of the moving map. The aircraft locator symbol on the moving map will be updated at $20 \mathrm{HZ}$ from a blending of the position received from the TSRV's Inertial Reference System (IRS) and from a Differential Global Positioning System (DGPS) receiver onboard the aircraft. The position will be updated once every 1 to 3 seconds with a DGPS correction transmitted via data link from a ground station.

Warning information that indicates occupied runways (AMASS hold bars) and positions of other traffic will be transmitted to the TSRV via data link automatically

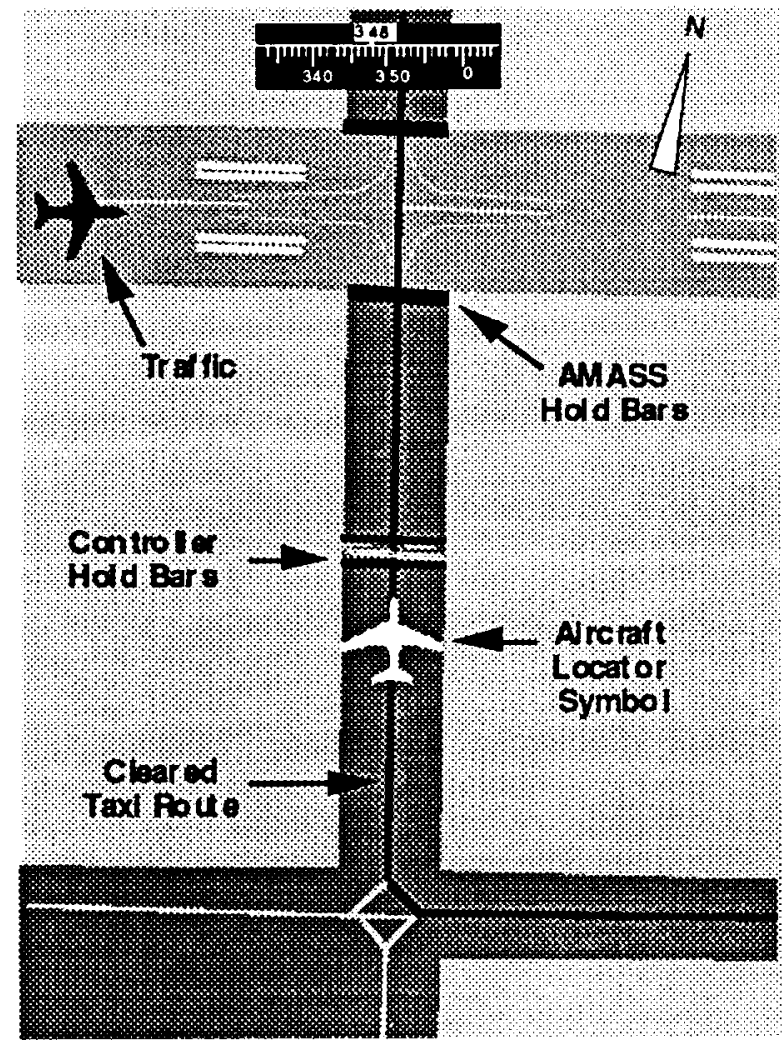

Figure 3. Elearonic moving map display. from the AMASS for display on the moving map. The positions of other traffic will be obtained from the ASDE-3 radar. The AMASS will filter the traffic data and only send the positions of the traffic which pose a safety threat to the TSRV. This might include all aircraft arriving or departing from the TSRV's designated approach or departure runway.

The cleared taxi route, modified routes, and hold bar status will be sent to the TSRV by a NASA provided controller via data link for display on the moving map. At all times during the demonstration, the TSRV will be under ACY FAA control. The NASA controller will monitor ACY control to determine what information to transmit to the aircraft. For this demonstration, the routes and modified routes will be predefined.

\section{CONCLUDING REMARKS}

The two efforts described here have been designed to address safety and capacity issues in the airport surface movement area. By working closely with the FAA and national airspace system companies and users on projects such as these, NASA LaRC can make effective use of its facilities while demonstrating advanced technologies.

\section{REFERENCES}

[1] Lyon, Ervin F.: Airport Surface Traffic Automation. The Lincoln Laboratory Joumal, vol. 4, no. 2, 1991 .

[2] VHF Data Link (VDL) Standards and Recommended Practices Ver. 1. Aeronautical Mobil Communications Panel/3 Report to Agenda Item 8, Appendix B, April 22, 1994.

[3] White, John J.: Advanced Transport Operating Systems Program. Proceedings of the Aerospace Technology Conference and Exposition, October, 1990.

[4] Go, George; and Ianniello, Joseph W:: Third Generation Airport Surface Detection Equipment Design. Proceedings of NAECON '94, May, 1994.

[5] Ianniello, Joseph W.; and Kruczek, Raymond M.: Airport Surface Collision Warning System Implementation. Proceedings of the 12th Digital Avionics Systems Conference, October, 1993.

[6] Batson, Vernon M.; Harris, Randall L.; and Hunt, Patricia J.: Navigating the Airport Surface: Electronic vs Paper Maps. Proceedings of the 13th Digital Avionics Systems Conference, October, 1994. 

